Article

\title{
Sustainable City and Community Empowerment through the Implementation of Community-Based Monitoring: A Conceptual Approach
}

\author{
Nur Khairlida Muhamad Khair ${ }^{1}$, Khai Ern Lee 1,2,3,* and Mazlin Mokhtar 1,3 \\ 1 Research Centre for Sustainability Science and Governance (SGK), Institute for Environment and \\ Development (LESTARI), Universiti Kebangsaan Malaysia, UKM Bangi 43600, Selangor, Malaysia; \\ n.khair@yahoo.com (N.K.M.K.); mazlin@ukm.edu.my (M.M.) \\ 2 Centre for Research and Instrumentation Management (CRIM), Universiti Kebangsaan Malaysia, \\ UKM Bangi 43600, Selangor, Malaysia \\ 3 Jeffrey Sachs Center on Sustainable Development, Sunway University, No.5, Jalan Universiti, \\ Bandar Sunway, Petaling Jaya 47500, Selangor, Malaysia \\ * Correspondence: khaiernlee@ukm.edu.my
}

Received: 27 September 2020; Accepted: 9 November 2020; Published: 17 November 2020

\begin{abstract}
A sustainable city should promote the active participation of its civil society in urban planning and development of cities as the means to satisfy their needs. However, the absence of an appropriate platform has caused the public to lose interest and neglect the process of planning and development. This article attempts to develop a conceptual framework for sustainable cities and communities' empowerment through the introduction of community-based monitoring as a means to increase community resilience and well-being. Community-based monitoring is designed to be instrumental in addressing environmental sustainability issues with public participation, where the community champions the environmental monitoring process for the decision making of planning and development of cities. The conceptual framework is expected to serve as an approach in driving the urban community towards attaining a more inclusive, safe, resilient, and sustainable environment.
\end{abstract}

Keywords: citizen science; community-based monitoring; Local Agenda 21; participation; sustainable cities; sustainable development

\section{Introduction}

Rapid urban development has induced many environmental problems at the local level, and it urgently needs to be monitored and addressed. Tackling environmental issues faced by the local community involves not only the local government or agencies, but also the active participation of the local community in environmental monitoring. This is in line with the concept of a sustainable city that involves not only environmental mitigation, but also the active participation of local citizens to interact with the policymakers to achieve a sustainable quality of life [1]. Specifically, the UN Sustainable Development Goals through SDG11 (Sustainable Cities and Communities) inspire urban sustainability that requires cities to be liveable and safe via integrated planning and management as well as citizen's participation [2]. Due to that, cities are increasingly paying their attention to the role of drivers for sustainable development.

Many collaborations between politics, research, business, and civil society have been developed in cities worldwide. However, in most public participation initiatives, programme managers face problems, especially in recruiting new participants and retaining the number of local community participation in a monitoring programme. This is due to loss of interest, lack of networking opportunities and information delivering to the public as well as funding availability [3-5]. The main issue behind 
these factors is related to the local community's motivation in environmental monitoring. As we fail to fully understand the values and motivations of surrounding communities, this will lead them to lose their interest, and the likelihood of sustaining community participation will never be achieved [6]. This will affect the capacity of community participation in integrated planning and management of the cities. People who have a strong sense of ownership for the community and the environment feel obliged to protect and care for the environment, and this includes practising sustainable behaviour and participating in local problem solving [7,8]. It is important when individuals feel ownership for a social entity (e.g., family, group, organisation or nation), as they are likely to engage in citizenship behaviour towards that entity. In other words, as individuals develop a sense of ownership in their local environment, they are more likely to contribute to the community's well-being voluntarily.

To bring urban development to the next level, an attitudinal study is required at the individual and institutional levels, focusing on long term solutions as well as developing a stronger sense of ownership for the environment and community [9]. Community-based monitoring can be used as a tool to include local citizens directly in the assessment of development and decision-making processes [6]. Besides that, few studies have shown that environmental monitoring has long-term outcomes, such as a greater sense of ownership and pride as well as increased capacities of individuals and organisations in the community to understand the complexities of environmental issues [10-12].

By taking the motivations into account and exploring how they relate to community-based monitoring projects in different cultures, project managers and technology designers may gain insights about how to encourage long-term voluntary participation whereby the project will be influenced by the cultural setting, the type of project, the volunteer population, and how the project is managed [6]. As a model of a sustainable city, the city should play a vital role in implementing sustainability concepts, both in city development and urban governance. It is crucial to reflect the sustainability agenda in the local action, particularly in enhancing active community participation in planning and management to achieve sustainable development. In this article, the authors frame the question of how to localise environmental sustainability agenda as stipulated in SDG11. They further answer how to enhance community empowerment through the participation in city planning and decision making, especially towards environmental issues. Community-based monitoring is deliberated as a means in empowering the local community to participate in environmental monitoring towards local planning for sustainable development whereby it creates awareness and a sense of ownership of the community towards the environment. Community-based monitoring can also be used as a tool in supporting the Local Agenda 21. It fits the purpose of public participation by enhancing the partnership between local authority and community, thus contributing to effective information delivery, and empowering public right in local planning $[13,14]$. With community-based monitoring in place, urban planning is not merely the responsibility of local authorities and government agencies; it empowers local communities to participate in environmental monitoring towards achieving the SDGs.

\section{Literature Review}

Urban areas vary from small cities to metropolitan areas in which the population living in urban areas has increased to about $55 \%$ of the world's population, and it is expected to increase to $68 \%$ by 2050 [15]. With the increase in urban population, urban lands need to be expanded where the habitats, biogeochemistry, hydrology, land cover and surface are needed for the development of infrastructures, transportations, housing and so forth. Cities are complex and are affected by many factors, such as economic, social and environmental factors, which could be contributors towards resource exploitation, social inequality and environmental degradation, cities can also be the platform that contributes to sustainable development [16].

The growing population has induced many environmental problems in recent years, leading to an increase in demand that urban development must be sustainable. SDG11 (Sustainable Cities and Communities) requires the cities to be liveable and safe, and this includes the capacity for participatory, integrated planning and management of the cities [17]. For local authorities and policymakers, 
the agreement on SDG11 marks a critical milestone to make cities sustainable. The targets of SDG11 are not only focusing on making the cities to be resilient in terms of the environment, but it covers the need for social integration into sustainable urban planning as translated in every target of SDG11 [17]. Meanwhile, the indicators will play a crucial role for the actors to assess and benchmark current progress towards the goal or target besides raising awareness, promoting public participation and improving communication among each other [18].

The current practice of social integration in most sustainable cities is public participation. In making urban sustainability into a reality, public participation is needed to improve the quality, legitimacy and capacity of environmental assessments and decisions on urban planning, and policymaking process [19-21]. However, numerous studies have discussed that the current practice of public participation in enabling social transformation and influencing the decision-making process is still weak $[2,22,23]$. This also includes the platform available for the public to participate as well as who has the privilege to participate in the decision making because there are some cases where only selected individuals are consulted during the decision making [22]. Hence, the actual public participation is not only a means in the democratic process, but it also emphasises that sustainable development requires a process that empowers people to achieve broad ownership of the ideas and initiatives in choosing solutions to the problems in the local environment. The word empowerment in this context refers to the collective action to improve the quality of life in a community [24]. The empowered community is able to create broad support for environmental and development issues at their place by providing adequate information that can influence local decision making [5].

With the increase in environmental concerns, community-based monitoring emerges as a public participation approach in environmental monitoring to achieve sustainability. Community-based monitoring can be defined as a process where concerned citizens, government agencies, industries, academia, community groups and local institutions collaborate to monitor, track and respond to the collective issues of community or environment $[5,25]$. In other words, the concept of community-based monitoring conveys a decentralisation of environmental management to the local level and promotes shared responsibilities. This type of monitoring programme is widely used in various fields, either in biodiversity conservation $[26,27]$, status assessment, impact assessment, processes, and physical environment $[26,28,29]$.

Many benefits of community-based monitoring have been recognised, among them are increased environmental democracy, scientific literacy, social capital, citizen inclusion in local issues, benefits to government and ecosystems being monitored. It makes environmental sustainability knowledge accessible to the local communities, and scientists will be more aware of local knowledge and expertise [30]. It also recognises that public support for environmental protection can be increased by building social capital through activities that lead to community engagement, agency connection, leadership building, problem-solving and identification of resources [5]. Not only local communities will benefit from the monitoring, but the government agencies will also benefit as community-based monitoring offers a cost-effective alternative monitoring process whereby monitoring can be undertaken over larger areas and during non-office hours with more inclusive of stakeholders [31]. It also notes that the engagement of stakeholders and local communities in community-based monitoring to plan and manage environment and development tend to get more participation in community development and have more influence on policymakers [32]. This is because when the communities can get involved, they indirectly "own" the project rather than a project that is brought in by external entities [11].

Hence, it is essential to carefully design and plan a suitable strategy for developing community-based monitoring. The most successful strategies for developing environmental monitoring are those that take into account the element of motivations and interests of the community [33]. The consideration of community motivations has proven to inspire the community to take care of their environment [34]. In this process, it requires the project manager to spend their time getting along with the community, taking into account their desired project outcomes, interests and needs [35]. In some cases, the project manager engages with the key individuals that are often most respected by all in 
the community, such as clergymen or any known and respected community members $[35,36]$. At this stage, the project manager should have gained an understanding of the community motivations which then inform the designation of community-based monitoring about the methods and instruments, and this includes the feeling of community which involves the engagement of participants with the project team.

\section{The Development of Conceptual Framework}

A few significant components are identified to develop the conceptual framework for sustainable cities and communities' empowerment through the implementation of community-based monitoring. The conceptual framework consists of four substantial elements, namely (a) social mapping of the community, (b) designing the community-based monitoring, (c) sustaining community-based monitoring in the long-term, and (d) the sustainability of community-based monitoring. The critical focus relies on the recognition that the conformation and implementation of any community-based monitoring is a participatory process where communities and government agencies are the main actors, and the researchers catalyse their interactions. The success of this strategy largely depends on dialogue, the interaction between the different participants involved and consensus on matters of public interest. In this sense, a conceptual framework is proposed to lay out the mechanisms that aim to acknowledge the necessity to build trust between people. The conceptual framework of community-based monitoring intends to support four pillars, namely:

(1) the development of social mapping to collect and socialise proper understanding of local community personalities and interests,

(2) the design of a people-centred environmental monitoring network assisted by manual and automated instrumentation,

(3) the act to sustain the monitoring programme by assessing the current policies related to the subject, and

(4) the communication and pedagogical strategies emerged and implemented during the process, to articulate the different members and sources of knowledge involved.

Figure 1 shows the conceptual framework for implementing community-based monitoring as a means for sustainable cities and communities.

\subsection{Social Mapping of the Community}

The mechanism proposed here considers the inclusion of motivations as a reflective path to design the criteria of the community-based monitoring where motivations are addressed from an individual perspective encompassing the inquiry of their personality as well as their concern on environmental issues. It aims to articulate scientific and popular knowledge, allowing to configure a social network for environmental monitoring consistent with the context and necessity of the community. This mechanism is inspired by a study of Arias et al. [37] who considers the inclusion of community's vulnerability as a reflective path into disaster prevention through an approach called social cartography, consisting an open dialogue between participants and the organisers to understand local vulnerability [37]. In the context of this conceptual framework, social cartography or social mapping is required to collectively reflect and discuss effective community-based monitoring through the identification of community motivations. In this sense, the path of social mapping is formulated from the need of strengthening ties between the local communities [38]. Through this process, the community can provide valuable inputs for a more integrated understanding of social motivations that can help to formulate monitoring strategies, and also help to identify the particular criteria of community-based monitoring according to community's preferences. The latter is fundamentally essential to achieve a greater sense of ownership in the network of the participants involved. Thus, the first element to be included in this conceptual framework is the motivation of the community, consisting of a sense of ownership, sense of community and environmental awareness. 


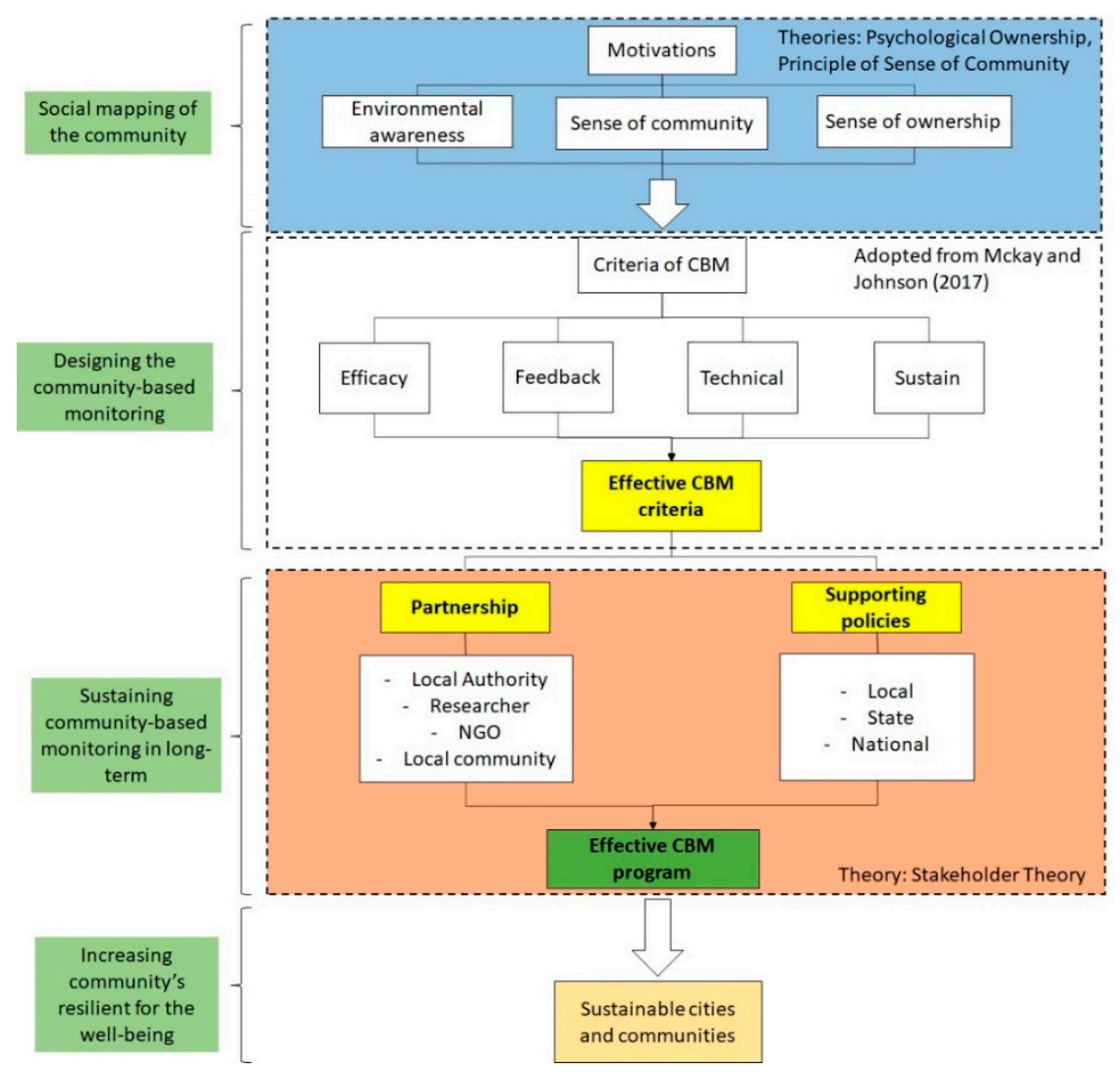

Figure 1. The conceptual framework for sustainable cities and communities' empowerment through the implementation of community-based monitoring.

\subsubsection{Sense of Ownership}

One of the fundamental elements in community-based monitoring is where the community can participate in most of the processes. As the community is treated as an equal partner in setting monitoring scope and framework, it promotes a greater sense of ownership over the problem. It is essential to maintain the level of community ownership so that the goals of the long-term sustainability of community-based monitoring will be achieved. The terminology of ownership has been widely explained in possessive tendencies and the perspective of mind [39-41]. Previous studies on ownership have explored various explanations concerning the relationship of ownership and impact on job satisfaction, commitment, intent to stay or citizenship behaviour [42-49]. Hence, it is a must to understand how the sense of ownership of an individual is developed.

People develop ownership based on the existence of psychological ownership motives of intra-individual functions in efficacy, self-identity and the need for having a place to dwell [41]. Three routes lead to psychological ownership, such as perceived control, knowledge and investment of self. This can be explained in the context of community-based monitoring when the community has the right to design their environmental monitoring programme, showing that the community experiences control and thus leads to ownership. As they perceive the control, they will develop the monitoring design, which is suitable for their capacity and the likelihood to sustain is higher [50]. Recognising the routes of psychological ownership, the theory of psychological ownership can be framed into a community-based monitoring framework which will help to fill the gap on the psychological argument of the actual problem to the symptom of less participation in public participation. Building the conceptual understanding from the theory of psychological ownership will help to develop a mechanism for effective community-based monitoring with a multidisciplinary approach. 


\subsubsection{Sense of Community}

Besides a sense of ownership, another factor that can affect community motivation is the sense of community. In this context, the community can be referred to as a group of people living together at a specific locality that connect and share resources and services. The community is also recognised as the most basic level of organisation of humans that builds physical and emotional aspects that are experienced by the community members [51]. This type of connection and emotional sentiment among the individuals in the community are recognised in social psychology study as a "sense of community" [52]. According to Bachrach and Zautra [53], the community that has a stronger sense of community tends to have a greater sense of purpose and perceived control. This can be seen through the high tendency of the community to participate and contribute their efforts to solving a problem which then benefits the community as a whole [54]. Due to that reason, it is essential to study the "sense of community", so that both the community and monitoring project team will have a better understanding of its influence on community-based monitoring as well as learning how to develop community spirit in a situation where its absence is a limitation to the fruition of community-based monitoring.

\subsubsection{Environmental Awareness}

Environmental awareness is a broad and abstract concept in measuring an individual's level of concern towards their environment, which can be related to environmental quality and health. It has been considered as one of the crucial steps in preparing people to solve environmental problems [55]. According to Harju-Autti [56], environmental awareness is a state of consciousness of their external surroundings in which they live and work. It also believes that the level of environmental awareness can impact the development and the way a person behaves, such as embarking on environmentally friendly actions. For example, people are willing to participate in environmental action when they perceive a threat that can affect their health quality [57]. Besides that, residents who feel their responsibility to take care of their environmental quality and maintain green spaces at their place are more likely to participate in environmental protection action [51].

As the concept of environmental awareness is too broad, it is impossible to measure the level of awareness of an individual directly. For example, Zhenmin and Xiaohua [57] study the level of Jiangsu residents' environmental awareness by looking at three main elements, which are environmental attitudes (the relationship between human and environment), environmental behaviour (action towards environmental friendly choice) and finally environmental knowledge (involves a basic understanding of environmental policies by the government). In the same vein, Partanen-Hartell et al. [58], they measure local communities' environmental awareness by focusing on three main elements, consisting of motivations (personal values and attitudes), knowledge (environmental knowledge in cause-effect relationships) and skills (personal abilities in environmental actions).

Understanding local community attitudes and behaviours, as well as their perceptions, are vital to impose the system related to the policy regarding environmental management as it later can result upon social and economic activities. Building upon the conceptual understanding of the local community's environmental awareness, this will help the project manager to design an appropriate method of environmental monitoring which in turn can help to increase local community environmental awareness.

\subsection{Designing Community-Based Monitoring}

The strategy for effective environmental monitoring constitutes the identification of appropriate elements of the surrounding environment, acknowledging the needs and the capacities of the local community, including their local knowledge as well as their motivations. Thus, as a second element in the conceptual framework, the design of an instrumental monitoring network where both local knowledge and scientific knowledge are recognised. Hence, the design of an instrumental network should consider not only technical requirements for an adequate installation and operation of the 
instrument, but also elements of the climate and risk perceptions from inhabitants and local authorities which identify the locations in their communities and livelihood. The design of community-based monitoring is based on effective criteria, such as efficacy, technicality, feedback, and sustainability which are adopted from a study by McKay and Johnson [6]. Each of the criteria proposed in this study will eventually reflect the motivations of the community gathered in the social mapping.

\subsubsection{Efficacy of Monitoring}

The utmost important element in instituting a monitoring plan is to identify goals and local interests. This includes framing the issues, determining research questions, and identifying suitable indicators for monitoring purposes [6,32,33,59-61]. As a participatory research process, the ethical approach of research should be understood where the residents have control in deciding what data will be collected to ensure that the information is relevant and worth to the residents [62]. For example, in Sub-Saharan Africa, the rural communities are interested in engaging in agricultural monitoring activities as it is the source of their livelihood [36]. Meanwhile, in the case of the aboriginal communities, at this stage, the traditional knowledge will be included and merged with scientific knowledge to complement each other [6].

Moreover, including the community at the very early step of establishing community-based monitoring will encourage them to develop ownership, foster learning, create a good rapport between the researchers, local community and other stakeholders [11,35,36,63]. At this stage, it is essential to develop common ground between the stakeholders as the planned objectives are needed in making sure that the project stays within the context. Besides that, a clear objective will lead to a long-term goal of monitoring activities [59]. After the project goals have been determined, the next move is to determine a suitable methodology that is compatible with local capacity by considering time and costs and identify monitoring indicators that are relevant to project goals and available resources, such as monitoring equipment [59]. The most crucial element here is that the communities understand how the monitoring indicators contribute to the project goals [36,59].

In most cases of community-based monitoring, the community is provided with a series of training and workshops which help them to build their capacity and capability in conducting scientific research $[11,35,64,65]$. Although there are criticisms on the credibility of data collected by the community, proper training and mentoring have shown that the community can produce monitoring data as reliable as those scientists [35]. Another critical element in ensuring the efficacy of monitoring is the control of data. The issue of data ownership often arises when there is no early discussion between the community and experts. Besides that, in some cases, the data are owned by the funder through a funding contract [66]; hence, a mutual agreement of data ownership should be determined at the early stage of monitoring planning. In particular, in the aboriginal community, traditional knowledge is owned by the community. Therefore, when it comes to the publication or use of data, the knowledge holders have to approve the data usage and access as it is an act of respect and honour to the community [66]. However, both experts and the community have distinct views in the context of data privacy, as usually, the data collected from the monitoring are valuable to the experts as their intellectual property. In contrast, the community values the collected data as a source for supporting the collective decision in local planning [59].

\subsubsection{Technicalities of Monitoring}

The main intention of standardisation in community-based monitoring is to increase its scientific credibility and validity. The standardisation mainly consists of monitoring protocols, procedures, manuals or monitoring plans. Besides that, the data collected from monitoring without using a standardised protocol produce less reliable and credible data [3]. Usually, monitoring protocols are designed for specific monitoring parameters whereby the designed protocols should be easy to understand, tested and suitable for the community, complete with supplementary resources, such as monitoring manuals and guidance materials [32]. In the survey conducted by Carlson and 
Cohen [64], the majority of the respondents who follow water monitoring protocol provided by their local government perceive that they are informing policy mostly because the parameters are selected based on a few items concerning community priorities, capacities of the monitoring equipment or resources, and the existing monitoring protocol standards by the central body. However, there are also some factors, such as lack of resources which include programme funding, monitoring equipment and expertise, which can directly affect the monitoring protocol [59].

\subsubsection{Feedback Mechanism}

Effective community-based monitoring must involve a mechanism for programme feedback whereby the feedback mechanism can be divided into two types, being programme assessment and information dissemination. The monitoring feedback is essential to assemble opinions, ideas, information and knowledge from various stakeholders where it can be used to improve monitoring mechanisms $[5,36,67]$. In the first feedback mechanism, which is programme assessment, it focuses on the arrangement of the team, the suitability of monitoring goals, indicators and the efficiency of monitoring protocols. At this stage, that gathered feedback will be used to update and make an appropriate adjustment to the rapidly changing condition that will affect community-based monitoring programmes $[59,68]$. The second feedback mechanism is information dissemination, where community-based monitoring focuses on the local initiative that monitoring results need to be fed immediately back to the local decision-makers [69]. Usually, after the monitoring activities have been carried out, the results are disseminated among the group members in which the feedback of the monitoring results is gathered at the community forums and meetings to invite more suggestions from their perspectives and obtain approval concerning appropriate management decisions [70]. For example, in a study of catchment monitoring in South Africa, the stakeholders at any level of participation are continuously updated with the current monitoring progress and findings through feedback forum [36]. To ensure the effectiveness of information dissemination, a suitable communication mechanism is required to educate the community about the values of community-based monitoring, and the importance of their contribution to producing an excellent collective decision.

\subsubsection{Sustainability of the Initiative}

One of the specific elements of community-based monitoring is the collaboration or partnership in carrying out monitoring activities. Establishing a partnership in community-based monitoring is essential to maintain the programme sustainability, whereby, in this case, a partnership can be formed with a wide variety of stakeholders that are relevant to the monitoring objectives [3,5,32,59]. It is essential to have a clear goal in community-based monitoring as it will help to determine who is the most suitable player for establishing partnership [3,64]. For example, the third sector or civil sector, known as NGOs, play an essential role, including advocacy, facilitation and brokerage, and service provision on societal work [71,72] that can provide the opportunities for citizens to get involved in environmental protection action at a smaller scale [62].

Several studies found that establishing collaborative effort in community-based monitoring is the key to the programme effectiveness [3,5,32]. Besides that, it also helps to increase the community's passion and resources, as well as to form a valuable social connection [32]. However, one should note that the success of community-based monitoring can only be achieved if they are context-specific, flexible, adaptive, recognising local needs, benefiting the community, considering community motivation and capacity in monitoring partnerships [32,73]. To sustain community participation in community-based monitoring, the communication mechanism between the group members and experts need to be considered because the programme partners, as well as experts, need to pay attention to community feedback throughout the programme, so that the community does not feel that they are ignored by the experts [74]. Despite many benefits from the partnership in community-based monitoring, however, according to Pollock and Whitelaw [32], to distribute responsibility equally among group members for project implementation is still challenging. 
Another critical element that is important for community-based monitoring sustainability is the funding aspect $[5,74,75]$. The process of monitoring activities requires some allocations to fund monitoring equipment and other miscellaneous costs related to the monitoring programme. To sustain community-based monitoring in a longer-term of implementation, the funding duration is seen as more important than the funding amount [32]. Monitoring the environment requires a long-term commitment of funding to make sure the monitoring programme is carried out smoothly and consistently whereby it needs commitments from local and regional institutions as well as government agencies with the support of academic institutions. Usually, the funding of community-based monitoring comes from government agencies, local businesses, and residents [6]; however, there are reports that most government agencies provide short-term funding which then will affect the effectiveness and sustainability of the programme [76]. Due to this reason, a community-based monitoring programme needs to build partnerships and collaborate with various stakeholders, such as NGOs, local and international organisations, and other community organisations as they can provide more resources and capacities than government agencies can provide [64].

\subsection{Sustaining Community-Based Monitoring in the Long-Term}

In the previous section, the criteria to sustain community-based monitoring by engaging various stakeholders which are in line with the monitoring objectives as well as considering securing a long-term funding scheme have been explored. In this section, the focus will be given to how to sustain community-based monitoring in the long term in the context of partnership, referring to the participation of selected partners as well as how it can influence the existing policies related to sustainable environmental management.

Specifically, the ultimate goal of community-based monitoring is to encourage the empowerment of the local community in local decision making, especially in environmental issues. Thus, to realise the goal, the responsibility of dealing with local environmental management must be shared among civil society and other stakeholders. The types of stakeholder chosen for partnership are those interested or affected groups where partnerships are vital in tackling the complex sustainable environmental issues which demand active involvement of various stakeholders. The complex environmental issues have called all sectors of the society to share efforts in forming a new configuration body to solve the problem within the local level [77]. Studies have revealed that partnerships can foster conservation action and learning as well as promote policy change $[77,78]$.

In the context of this conceptual framework, the project manager needs to focus on creating the partnership dynamics right from the start by getting the right partners on board, creating a common understanding and shared vision to make sure that participants recognise their dependence on each other and innovative collective thinking to solve the problem. A successful partnership in community-based monitoring depends upon the strategy which can produce a valuable contribution of collective innovative thinking that can help to improve the existing policy on environmental management. Besides that, the strategy should include effective communications with the partners as well as information dissemination by the media [60]. To influence the existing policy on environmental management, the availability of current and good quality data is vital as the lack of relevant environmental data on specific issues may cause it to be challenging for policymakers to formulate the policies and develop the monitoring systems [79]. Through the built partnership of various stakeholders in community-based monitoring, it will help to determine what kind of relevant data is needed to broaden the list of environmental monitoring indicators, what capacities to gather, as well as how to compile and effectively use the data at the city or state levels. Although the monitoring activities are context-specific to a particular locality and focusing on a subnational level, these collected data can also benefit the policymakers and developers in their analysis at a higher level, such as the national level. 


\subsection{Increasing the Community's Resilient for the Well-Being}

The last section in the conceptual framework is the desired goal of community-based monitoring to achieve, which is sustainable cities and communities. As sustainable development has become the mainstream agenda of the world, an abundance of studies has been published to explore how to adopt sustainable development practices into the communities' lives [80-83]. For example, sustainable communities can be understood as a concept of sustaining human existence on the planet by improving the quality of life [84]. In this way, sustainable communities can be achieved as citizen quality of life is improved. With the establishment of SDG11 focusing on the sustainability of the cities as well as their communities, cities are striving to improve their performance from unsustainable practices to a more sustainable lifestyle. However, the implementation of sustainable development agenda is not merely subjected to the national government, and this shared vision is also reflected in Local Agenda 21 initiatives that demonstrate the willingness of local actors to adopt more sustainable policies and practices. Therefore, in the context of this conceptual framework, community-based monitoring acts as a tool designed with extensive local community participation, serving as a proactive initiative that assists the local government in mobilising the community to solve environmental issues in the local setting. Through community-based monitoring, communities are directly involved in most of the stages of the programme, including planning, carrying out monitoring, interpreting the result, and decision-making together with the relevant stakeholders to determine appropriate action for the issues. At the same time, it builds ownership and sense of belonging of the community as well as increase awareness level towards their environment, helping to create inclusive and sustainable urbanisation, capacity for participatory, as well as integrated and sustainable human settlement planning and management.

Although community-based monitoring focuses on a smaller scale, such as locally based issues, it also supports the Local Agenda 21 through effective information delivery, especially on public rights in local environmental management planning. As shown in Table 1, community-based monitoring can help to fit a few programme areas into Chapter 8: Integrating environment and development in decision making. Out of four programme areas in this chapter, there are two that are relevant to the context of community-based monitoring. The first programme area is integrating environment and development at the policy, planning and management levels which can be conducted by community-based monitoring through the integration of multidisciplinary stakeholders in seeking the best solution for the issues. The second programme area is focusing on establishing systems for integrated environmental and economic accounting in which to integrate the environment into economic accounting framework; the availability of environmental data is essential. Through community-based monitoring, the results from monitoring can help to provide data needed for environmental accounting. Eventually, the monitoring data can help the government either national or subnational, to allocate appropriate budgets for environmental purposes, and this will increase the efficiency of the distribution of the financial resources as well as prevent fraud. 
Table 1. Programme areas of Chapter 8 in the Local Agenda 21.

\begin{tabular}{|c|c|c|c|c|}
\hline Programme Areas & & Objectives & & Activities \\
\hline $\begin{array}{l}\text { Integrating environment and } \\
\text { development at the policy, } \\
\text { planning and management } \\
\text { levels }\end{array}$ & (d) & $\begin{array}{l}\text { To conduct a national review } \\
\text { of economic, sectoral and } \\
\text { environmental policies, } \\
\text { strategies and plans to } \\
\text { ensure the progressive } \\
\text { integration of environmental } \\
\text { and development issues. } \\
\text { To strengthen institutional } \\
\text { structures to allow the full } \\
\text { integration of environmental } \\
\text { and developmental issues, at } \\
\text { all levels of decision-making. } \\
\text { To develop or improve } \\
\text { mechanisms to facilitate the } \\
\text { involvement of concerned } \\
\text { individuals, groups and } \\
\text { organisations in } \\
\text { decision-making at all levels. } \\
\text { To establish domestically } \\
\text { determined procedures to } \\
\text { integrate environment and } \\
\text { development issues } \\
\text { in decision-making. }\end{array}$ & $\begin{array}{l}\text { (a) } \\
\text { (b) } \\
\text { (c) } \\
\text { (d) }\end{array}$ & $\begin{array}{l}\text { Improving } \\
\text { decision-making processes } \\
\text { Improving planning and } \\
\text { management systems } \\
\text { Data and information } \\
\text { Adopting a national strategy for } \\
\text { sustainable development }\end{array}$ \\
\hline $\begin{array}{l}\text { Establishing systems for } \\
\text { integrated environmental and } \\
\text { economic accounting }\end{array}$ & (a) & $\begin{array}{l}\text { To expand existing systems } \\
\text { of national economic } \\
\text { accounts to integrate } \\
\text { environmental and social } \\
\text { dimensions in the } \\
\text { accounting framework }\end{array}$ & $\begin{array}{l}\text { (a) } \\
\text { (b) } \\
\text { (c) } \\
\text { (d) } \\
\text { (e) }\end{array}$ & $\begin{array}{l}\text { Strengthening } \\
\text { international cooperation } \\
\text { Strengthening national } \\
\text { accounting systems } \\
\text { Establishing an } \\
\text { assessment process } \\
\text { Strengthening data and } \\
\text { information collection } \\
\text { Strengthening } \\
\text { technical cooperation }\end{array}$ \\
\hline
\end{tabular}

Source: United Nations [85].

\section{Conclusions}

In this article, we sought to address the question of how to localise sustainable development initiatives in achieving sustainable cities and communities. Community-based monitoring is proposed as a tool in driving the direct participation of the local community. Through community-based monitoring, the involvement of the local community is not only restricted to monitoring activities, it encompasses almost every stage of community-based monitoring. A conceptual framework of community-based monitoring is laid out by considering four main elements, including (i) social mapping, (ii) designing of community-based monitoring, (iii) sustaining community-based monitoring in the long-term, and (iv) increasing community resilient for well-being.

In the first section of the conceptual framework, the effectiveness of community-based monitoring hugely depends on the community's motivation, whereby the motivation of the community will determine the longevity of the monitoring programme. Besides that, the community's motivation also affects the types of criteria and monitoring subjects as it depends on the community's interest. In the process of designing community-based monitoring, it is essential for the project manager to carefully design as well as continuously engage the local community to get their feedback on the suitability of the monitoring activities. This is an essential phase in which the design of the monitoring programme 
will subsequently affect the quality of data produced, as the low-quality data will result in an invalid outcome and the decision made may not reflect the actual situation.

To sustain community-based monitoring in the long term is crucial in which the participation of various stakeholders in the programme needs strong partnerships which enables the community and the experts have an opportunity to interact, share knowledge, ideas, develop new skills and come out with a collective decision on the issues to influence the existing policies related to environmental issues. Although community-based monitoring focuses on a smaller scale or locally-based issues, it also helps to fill the loopholes of data availability issues at the state level. All in all, community-based monitoring not only benefits the local community by providing the platform to engage in environmental management directly, but it also helps local authorities towards the sustainable cities and Local Agenda 21 at the same time.

Author Contributions: N.K.M.K.: Methodology, Conceptualisation, Investigation, Writing-Original Draft. K.E.L.: Conceptualisation, Methodology, Validation, Investigation, Resources, Writing-Review and Editing, Supervision, Funding acquisition. M.M.: Investigation, Supervision. All authors have read and agreed to the published version of the manuscript.

Funding: This research was funded by Universiti Kebangsaan Malaysia, through Geran Universiti Penyelidikan (GUP-2017-016) and the APC was funded by PP-LESTARI-2020.

Acknowledgments: The authors would like to acknowledge the financial support for this study provided by Universiti Kebangsaan Malaysia, through Geran Universiti Penyelidikan (GUP-2017-016) and PP-LESTARI-2020.

Conflicts of Interest: The authors declare no conflict of interest.

\section{References}

1. Dassen, T.; Kunseler, E.; van Kessenich, L.M. The sustainable City: An analytical-deliberative approach to assess policy in the context of sustainable urban development. Sustain. Dev. 2013, 21, 193-205. [CrossRef]

2. Lee, K.E.; Abdullah, R.; Hanafiah, M.M.; Halim, A.A.; Mokhtar, M.; Goh, C.T.; Alam, L. An integrated approach for stakeholder participation in watershed management. In Environmental Risk Analysis for Asian-Oriented, Risk-Based Watershed Management; Yoneda, M., Mokhtar, M., Eds.; Springer: Singapore, 2018; pp. 35-143.

3. Conrad, C.T.; Daoust, T. Community-based monitoring frameworks: Increasing the effectiveness of environmental stewardship. Environ. Manag. 2008, 41, 358-366. [CrossRef] [PubMed]

4. Milne, R.; Rosolen, S.; Whitelaw, G.; Bennett, L. Multi-party monitoring in Ontario: Challenges and emerging solutions. Environments 2006, 34, 11-23.

5. Whitelaw, G.; Vaughan, H.; Craig, B.; Atkinson, D. Establishing the Canadian community monitoring network. Environ. Monit. Assess. 2003, 88, 409-418. [CrossRef] [PubMed]

6. McKay, A.J.; Johnson, C.J. Identifying effective and sustainable measures for community-based environmental monitoring. Environ. Manag. 2017, 60, 484-495. [CrossRef]

7. Lachapelle, P.R.; McCool, S.F. Exploring the concept of "ownership" in natural resource planning. Soc. Nat. Resour. 2017, 18, 279-285. [CrossRef]

8. Süssenbach, S.; Kamleitner, B. Psychological ownership as a facilitator of sustainable behaviors. In Psychological Ownership And Consumer Behavior; Springer: Cham, Swizerland, 2018; pp. 211-225.

9. Chew, G.K. Community Engagement to Promote Environmental Ownership and Secure Our Future. In 50 Years of Environment: Singapore's Journey Towards Environmental Sustainability, 2nd ed.; Tan, Y.S., Ed.; World Scientific Publishing Co. Pte. Ltd.: Singapore, 2016; pp. 193-220.

10. Chari, R.; Matthews, L.J.; Blumenthal, M.; Edelman, A.F.; Jones, T. The Promise Of Community Citizen Science; RAND: Santa Monica, CA, USA, 2017.

11. Loh, P.; Sugerman-Brozan, J.; Wiggins, S.; Noiles, D.; Archibald, C. From asthma to AirBeat: Community-driven monitoring of fine particles and black carbon in Roxbury, Massachusetts. Environ. Health Perspect. 2002, 110, 297-301. [CrossRef]

12. Sheppard, S.A.; Terveen, L. October. Quality is a verb: The operationalisation of data quality in a citizen science community. In Proceedings of the 7th International Symposium on Wikis and Open Collaboration, ACM 2011, Mountain View, CA, USA, 3-5 October 2011; pp. 29-38. 
13. Coenen, F. Local Agenda 21: 'meaningful and effective' participation? In Public Participation and Better Environmental Decisions; Springer: Dordrecht, The Netherlands, 2009; pp. 165-182.

14. Barrett, B.; Usui, M. Local Agenda 21 in Japan: Transforming local environmental governance. Local Environ. 2002, 7, 49-67. [CrossRef]

15. United Nations. 68\% of the World Population Projected to Live in Urban Areas by 2050, United Nations Department of Economic and Social Affairs. United Nations Department of Economic and Social Affairs, (UN DESA). 2018. Available online: https://www.un.org/development/desa/en/news/population/2018revision-of-world-urbanization-prospects.html (accessed on 25 March 2019).

16. Parnell, S. Defining a global urban development agenda. World Dev. 2016, 78, 529-540. [CrossRef]

17. United Nations. Cities. Sustain. Dev. Action 2015. United Nations Sustainable Development. 2016. Available online: https://www.un.org/sustainabledevelopment/cities/ (accessed on 20 March 2019).

18. Pires, S.M.; Fidélis, T.; Ramos, T.B. Measuring and comparing local sustainable development through common indicators: Constraints and achievements in practice. Cities 2014, 39, 1-9. [CrossRef]

19. Dietz, T.; Stern, P.C. Public Participation in Environmental Assessment and Decision Making; National Academies Press: Washington, DC, USA, 2008.

20. Gaventa, J.; Barrett, G. Mapping the outcomes of citizen engagement. World Dev. 2012, 40, $2399-2410$. [CrossRef]

21. Ostrom, E. Governing the Commons: The Evolution of Institutions for Collective Action; Cambridge University Press: Cambridge, UK, 1990.

22. Cornwall, A. Unpacking 'Participation': Models, meanings and practices. Community Dev. J. 2008, 43, 269-283. [CrossRef]

23. Fiorino, D.J. Citizen participation and environmental risk: A survey of institutional mechanisms. Sci. Technol. Hum. Values 1990, 15, 226-243. [CrossRef]

24. Perkins, D.D.; Zimmerman, M.A. Empowerment theory, research, and application. Am. J. Community Psychol. 1995, 23, 569-579. [CrossRef] [PubMed]

25. Bonney, R.; Cooper, C.B.; Dickinson, J.; Kelling, S.; Phillips, T.; Rosenberg, K.V.; Shirk, J. Citizen science: A developing tool for expanding science knowledge and scientific literacy. BioScience 2009, 59, 977-984. [CrossRef]

26. Conrad, C.C.; Hilchey, K.G. A review of citizen science and community-based environmental monitoring: Issues and opportunities. Environ. Monit. Assess. 2011, 176, 273-291. [CrossRef]

27. Sultana, P.; Abeyasekera, S. Effectiveness of participatory planning for community management of fisheries in Bangladesh. J. Environ. Manag. 2008, 86, 201-213. [CrossRef]

28. Roy, H.E.; Pocock, M.J.; Preston, C.D.; Roy, D.B.; Savage, J.; Tweddle, J.C.; Robinson, L.D. Understanding Citizen Science and Environmental Monitoring: Final Report on Behalf of UK Environmental Observation Framework; UK Centre for Ecology \& Hydrology: Lancaster, UK, 2012.

29. Wilson, J.J.; Jisming-See, S.W.; Brandon-Mong, G.J.; Lim, A.H.; Lim, V.C.; Lee, P.S.; Sing, K.W. Citizen science: The first Peninsular Malaysia butterfly count. Biodivers. Data J. 2015, e7159. [CrossRef]

30. Carolan, M.S. Science, expertise, and the democratisation of the decision-making process. Soc. Nat. Resour. 2006, 19, 661-668. [CrossRef]

31. Lawrence, L.; Debbie, A.; Deagen, R. Choosing public participation methods for natural resources: A context-specific guide. Soc. Nat. Resour. 2001, 14, 857-872. [CrossRef]

32. Pollock, R.M.; Whitelaw, G.S. Community-based monitoring in support of local sustainability. Local Environ. 2005, 10, 211-228. [CrossRef]

33. Krasny, M.E.; Russ, A.; Tidball, K.G.; Elmqvist, T. Civic ecology practices: Participatory approaches to generating and measuring ecosystem services in cities. Ecosyst. Serv. 2014, 7, 177-186. [CrossRef]

34. Cuthill, M. An interpretive approach to developing volunteer-based coastal monitoring programmes. Local Environ. 2000, 5, 127-137. [CrossRef]

35. Walker, D.; Forsythe, N.; Parkin, G.; Gowing, J. Filling the observational void: Scientific value and quantitative validation of hydrometeorological data from a community-based monitoring programme. J. Hydrol. 2016, 538, 713-725. [CrossRef]

36. Kongo, V.M.; Kosgei, J.R.; Jewitt, G.P.W.; Lorentz, S.A. Establishment of a catchment monitoring network through a participatory approach in a rural community in South Africa. Hydrol. Earth Syst. Sci. 2010, 14, 2507-2525. [CrossRef] 
37. Arias, P.A.; Villegas, J.C.; Machado, J.; Serna, A.M.; Vidal, L.M.; Vieira, C.; Cadavid, C.A.; Vieira, S.C.; Ángel, J.E.; Mejía, Ó.A. Reducing social vulnerability to environmental change: Building trust through social collaboration on environmental monitoring. Weather Clim. Soc. 2016, 8, 57-66. [CrossRef]

38. Gloeckner, H.; Mkanga, M.; Ndezi, T. Local empowerment through community mapping for water and sanitation in Dar es Salaam. Environ. Urban. 2004, 16, 185-198. [CrossRef]

39. Etzioni, A. The socio-economics of property. J. Soc. Behav. Personal. 1991, 6, 465-468.

40. Furby, L. Understanding the psychology of possession and ownership: A personal memoir and an appraisal of our progress. J. Soc. Behav. Personal. 1991, 6, 457.

41. Pierce, J.L.; Kostova, T.; Dirks, K.T. The state of psychological ownership: Integrating and extending a century of research. Rev. Gen. Psychol. 2003, 7, 84-107. [CrossRef]

42. Ajzen, I. Perceived behavioral control, self-efficacy, locus of control, and the theory of planned behavior 1 . J. Appl. Soc. Psychol. 2002, 32, 665-683. [CrossRef]

43. Matilainen, A.; Pohja-Mykrä, M.; Lähdesmäki, M.; Kurki, S. “I feel it is mine!"-Psychological ownership in relation to natural resources. J. Environ. Psychol. 2017, 51, 31-45. [CrossRef]

44. O'driscoll, M.P.; Pierce, J.L.; Coghlan, A.M. The psychology of ownership: Work environment structure, organisational commitment, and citizenship behaviours. Group Organ. Manag. 2006, 31, 388-416. [CrossRef]

45. Parker, S.K.; Wall, T.D.; Jackson, P.R. "That's not my job": Developing flexible employee work orientations. Acad. Manag. J. 1997, 40, 899-929. [CrossRef]

46. Pendleton, A.; Wilson, N.; Wright, M. The perception and effects of share ownership: Empirical evidence from employee buy-outs. Br. J. Ind. Relat. 1998, 36, 99-123. [CrossRef]

47. Pierce, J.L.; Rodgers, L. The psychology of ownership and worker-owner productivity. Group Organ. Manag. 2004, 29, 588-613. [CrossRef]

48. Vandewalle, D.; Van Dyne, L.; Kostova, T. Psychological ownership: An empirical examination of its consequences. Group Organ. Manag. 1995, 20, 210-226. [CrossRef]

49. Wagner, S.H.; Parker, C.P.; Christiansen, N.D. Employees that think and act like owners: Effects of ownership beliefs and behaviors on organisational effectiveness. Pers. Psychol. 2003, 56, 847-871. [CrossRef]

50. Portschy, S. Community participation in sustainable urban growth, case study of Almere, The Netherlands. Pollack Periodica 2016, 11, 145-155. [CrossRef]

51. Zanetell, B.A.; Knuth, B.A. Participation rhetoric or community-based management reality? Influences on willingness to participate in a Venezuelan freshwater fishery. World Dev. 2004, 32, 793-807. [CrossRef]

52. Chavis, D.M.; Hogge, J.H.; McMillan, D.W.; Wandersman, A. Sense of community through Brunswik's lens: A first look. J. Community Psychol. 1986, 14, 24-40. [CrossRef]

53. Bachrach, K.M.; Zautra, A.J. Coping with a community stressor: The threat of a hazardous waste facility. J. Health Soc. Behav. 1985, 26, 127-141. [CrossRef] [PubMed]

54. McMillan, D.W. Sense of community. J. Community Psychol. 1996, 24, 315-325. [CrossRef]

55. Ramsey, J.M.; Hungerford, H.R.; Volk, T.L. Environmental education in the K-12 curriculum: Finding a niche. J. Environ. Educ. 1992, 23, 35-45. [CrossRef]

56. Harju-Autti, P. Measuring Environmental Awareness in Nineteen States in India. Univ. J. Environ. Res. Technol. 2013, 3, 544-554.

57. Feng, Z.; Wang, X. Survey and evaluation on residents' environmental awareness in Jiangsu Province of China. Int. J. Environ. Pollut. 2002, 17, 312-322. [CrossRef]

58. Partanen-Hertell, M.; Harju-Autti, P.; Kreft-Burman, K.; Pemberton, D. Raising Environmental Awareness in the Baltic Sea Area; The Finnish Environment Institute: Helsinki, Finland, 1999.

59. Bliss, J.; Aplet, G.; Hartzell, C.; Harwood, P.; Jahnige, P.; Kittredge, D.; Lewandowski, S.; Soscia, M.L. Community-based ecosystem monitoring. J. Sustain. For. 2001, 12, 143-167. [CrossRef]

60. Dickinson, J.L.; Shirk, J.; Bonter, D.; Bonney, R.; Crain, R.L.; Martin, J.; Phillips, T.; Purcell, K. The current state of citizen science as a tool for ecological research and public engagement. Front. Ecol. Environ. 2012, 10, 291-297. [CrossRef]

61. McKinley, D.C.; Miller-Rushing, A.J.; Ballard, H.L.; Bonney, R.; Brown, H.; Cook-Patton, S.C.; Evans, D.M.; French, R.A.; Parrish, J.K.; Phillips, T.B.; et al. Citizen science can improve conservation science, natural resource management, and environmental protection. Biol. Conserv. 2017, 208, 15-28. [CrossRef]

62. Kruger, L.E.; Shannon, M.A. Getting to know ourselves and our places through participation in civic social assessment. Soc. Nat. Resour. 2000, 13, 461-478. [CrossRef] 
63. Burgos, A.; Páez, R.; Carmona, E.; Rivas, H. A systems approach to modeling community-based environmental monitoring: A case of participatory water quality monitoring in rural Mexico. Environ. Monit. Assess. 2013, 185, 10297-10316. [CrossRef] [PubMed]

64. Carlson, T.; Cohen, A. Linking community-based monitoring to water policy: Perceptions of citizen scientists. J. Environ. Manag. 2018, 219, 168-177. [CrossRef] [PubMed]

65. Buckland-Nicks, A.; Castleden, H.; Conrad, C. Aligning community-based water monitoring program designs with goals for enhanced environmental management. J. Sci. Commun. 2016, 15, A01. [CrossRef]

66. Gérin-Lajoie, J.; Herrmann, T.M.; MacMillan, G.A.; Hébert-Houle, É.; Monfette, M.; Rowell, J.A.; Anaviapik Soucie, T.; Snowball, H.; Townley, E.; Lévesque, E.; et al. IMALIRIJIIT: A community-based environmental monitoring program in the George River watershed, Nunavik, Canada. Écoscience 2018, 25, 381-399. [CrossRef]

67. Gomani, M.C.; Dietrich, O.; Lischeid, G.; Mahoo, H.; Mahay, F.; Mbilinyi, B.; Sarmett, J. Establishment of a hydrological monitoring network in a tropical African catchment: An integrated participatory approach. Phys. Chem. Earth Parts A/B/C 2010, 35, 648-656. [CrossRef]

68. Overdevest, C.; Orr, C.H.; Stepenuck, K. Volunteer stream monitoring and local participation in natural resource issues. Hum. Ecol. Rev. 2004, 11, 177-185.

69. Danielsen, F.; Burgess, N.D.; Balmford, A. Monitoring matters: Examining the potential of locally based approaches. Biodivers. Conserv. 2005, 14, 2507-2542. [CrossRef]

70. Danielsen, F.; Burgess, N.D.; Jensen, P.M.; Pirhofer-Walzl, K. Environmental monitoring: The scale and speed of implementation varies according to the degree of people's involvement. J. Appl. Ecol. 2010, 47, 1166-1168. [CrossRef]

71. Hassan, M.M.; Lee, K.E.; Mokhtar, M. Streamlining non-governmental organisations' programs towards achieving the sustainable development goals: A conceptual framework. Sustain. Dev. 2019, 27, 401-408. [CrossRef]

72. Hassan, M.M.; Lee, K.E.; Mokhtar, M. Mainstreaming, Institutionalising and Translating Sustain. Dev. Goals into Non-Governmental Organization's Programs. In Concepts and Approaches for Sustainability Management; Lee, K.E., Ed.; Springer: Cham, Switzerland, 2020; pp. 93-118.

73. Johnson, N.; Alessa, L.; Gearheard, S.; Gofman, V.; Kliskey, A.; Pulsifer, P.; Svoboda, M. Strengthening Community-Based Monitoring in the Arctic: Key Challenges and Opportunities; A Community White Paper Prepared for the Arctic Observing Summit; Arctic Institute of North America, University of Calgary: Calgary, AB, Canada, 2013.

74. Rotman, D.; Hammock, J.; Preece, J.; Hansen, D.; Boston, C.; Bowser, A.; He, Y. Motivations affecting initial and long-term participation in citizen science projects in three countries. iConf. 2014 Proc. 2014, 110-124. [CrossRef]

75. Sharpe, A.; Conrad, C. Community based ecological monitoring in Nova Scotia: Challenges and opportunities. Environ. Monit. Assess. 2006, 113, 395-409. [CrossRef] [PubMed]

76. McNeil, T.C.; Rousseau, F.R.; Hildebrand, L.P. Community-based environmental management in Atlantic Canada: The impacts and spheres of influence of the Atlantic Coastal Action Program. Environ. Monit. Assess. 2006, 113, 367-383. [CrossRef] [PubMed]

77. Van Huijstee, M.M.; Francken, M.; Leroy, P. Partnerships for sustainable development: A review of current literature. Environ. Sci. 2007, 4, 75-89. [CrossRef]

78. Danielsen, F.; Burgess, N.D.; Balmford, A.; Donald, P.F.; Funder, M.; Jones, J.P.; Alviola, P.; Balete, D.S.; Blomley, T.O.M.; Brashares, J.; et al. Local participation in natural resource monitoring: A characterisation of approaches. Conserv. Biol. 2009, 23, 31-42. [CrossRef] [PubMed]

79. Jaeger, A.; Zusman, E.; Nakano, R.; Nagano, A.; Dedicatoria, R.M.; Asakawa, K. Filling Environmental Data Gaps for SDG 11: A survey of Japanese and Philippines cities with recommendations. In Achieving and Sustaining SDGs 2018 Conference: Harnessing the Power of Frontier Technology to Achieve the Sustain. Dev. Goals (ASSDG 2018); Atlantis Press: Paris, France, 2019.

80. Magis, K. Community resilience: An indicator of social sustainability. Soc. Nat. Resour. 2010, 23, 401-416. [CrossRef]

81. Marchese, D.; Reynolds, E.; Bates, M.E.; Morgan, H.; Clark, S.S.; Linkov, I. Resilience and sustainability: Similarities and differences in environmental management applications. Sci. Total Environ. 2018, 613, 1275-1283. [CrossRef] 
82. Middlemiss, L.; Parrish, B.D. Building capacity for low-carbon communities: The role of grassroots initiatives. Energy Policy 2010, 38, 7559-7566. [CrossRef]

83. Raco, M. Securing sustainable communities: Citizenship, safety, and sustainability in the new urban planning. Eur. Urban Reg. Stud. 2007, 14, 305-320. [CrossRef]

84. Roseland, M. Toward Sustainable Communities: Solutions for Citizens and Their Governments; New Society Publishers: Gabriola, BC, Canada, 2012.

85. United Nations. United Nations Conference on Environment \& Development Rio de Janerio, Brazil, 3-14 June 1992, Agenda 21. 1992. Available online: https://sustainabledevelopment.un.org/content/documents/ Agenda21.pdf (accessed on 9 January 2020).

Publisher's Note: MDPI stays neutral with regard to jurisdictional claims in published maps and institutional affiliations.

(C) 2020 by the authors. Licensee MDPI, Basel, Switzerland. This article is an open access article distributed under the terms and conditions of the Creative Commons Attribution (CC BY) license (http://creativecommons.org/licenses/by/4.0/). 